\title{
ANALISIS FAKTOR PENYEBAB KETERLAMBATAN PROYEK BANGUNAN GEDUNG PEMERINTAH DI KOTA BUKITTINGGI
}

\author{
DEDDY KURNIAWAN ${ }^{1}$, RUDI $^{2}$ \\ Fakultas Teknik, Universitas Muhammadiyah Sumatera Barat ${ }^{1,2}$ \\ email: deddykurniawan@umsb.ac.id ${ }^{1}$, usahakita@ yahoo.com ${ }^{2}$
}

\begin{abstract}
Abstrak: Dalam pelaksanaan proyek konstruksi tepat waktu, dapat dipastikan menguntungkan kedua belah pihak, oleh sebab itu perusahaan yang baik akan selalu berusaha melaksanakan sesuai waktu yang telah ditetapkan atau berusaha meminimalkan keterlambatan dengan memilih tindakan koreksi yang perlu dilakukan dan mengambil keputusan berdasarkan analisa dari berbagai faktor. Oleh sebab itu diperlukan penelitian untuk mengidentifikasi dan menganalisa faktor-faktor yang mempengaruhi pelaksanaan proyek. Hasil analisa data menunjukan ada enam sub faktor utama yang sangat berpengaruh terhadap kinerja waktu pelaksanaan proyek konstruksi gedung di kota Bukittinggi, sub faktor tersebut adalah Keterlambatan pengiriman Barang dengan nilai Eigen Value sebesar 28,269 \%, Kekurangan Bahan Konstruksi dengan nilai Eigen Value sebesar 16,294 \%, Kualitas Bahan yang kurang baik dengan nilai Eigen Value sebesar 13,492\%, Kerusakan bahan ditempat penyimpanan dengan nilai Eigen Value sebesar 7,796 \%, Ketidak tepatan waktu pemesanan dengan nilai Egien Valua sebesar 6,648 \%, Keterlambatan pengiriman / penyediaan peralatan dengan nilai Eigen Value sebesar 6,466 \% Untuk mengatasi keterlambatan ini, pihak - pihak yang terlibat dalam pembangunan proyek konstruksi gedung harus melakukan beberapa cara atau strategi diantaranya : Penjadwalan pengiriman material yang harus benar benar tersusun dengan teratur dan efektif, mengantisipasi dengan cepat terhadap kekurangan maerial dilapangan, menjaga kualitas barang yang dikirim ke proyek agar mengikuti spesifikasi yang ada, menyediakan tempat penyimpanan material yang layak dan memadai, menyusun jadwal permintaan material dari lapangan yang tepat, menyediakan peralatan utama yang dibutuhkan sesuai dengan waktu pelaksanaan pekerjaan .
\end{abstract}

Kata Kunci : Management konstruksi, Faktor keterlambatan waktu

Abstract: In the implementation of construction projects on time, can certainly be beneficial for both parties, therefore a good company will always try to carry out according to a predetermined time or try to minimize delays by choosing corrective actions that need to be done and make decisions based on analysis of various factors. Therefore, research is needed to identify and analyse the factors that influence project implementation. The results of data analysis shows that there are six main sub factors that greatly affect the time performance of building construction projects in the city of Bukittinggi, these sub factors are Delays in the delivery of Goods with Eigen Value of 28.269\%, Lack of Construction Materials with Eigen Value of 16.294\%, Quality Material that is not good with Eigen Value value of 13,492\%, Damage to material in storage with Eigen Value of 7,796\%, Inaccuracy of order with Eigen value of 6,648\%, Delay in delivery / provision of equipment with Eigen Value value of 6,466\% To overcome This delay, the parties involved in the construction of a building construction project must carry out several ways or strategies including: Scheduling of material delivery that must be properly arranged in an orderly and effective manner, anticipating quickly the material deficiencies in the field, maintaining quality charcoal sent to the project to follow the specifications, provide adequate and adequate material storage, arrange a schedule of material requests from the right field, provide the main equipment needed in accordance with 
Vol. 2 No.1 Januari 2019

http://jurnal.umsb.ac.id/index.php/RANGTEKNIKJOURNAL

the time of execution.

Keywords: construction management, time delay factor

\section{PENDAHULUAN}

Pada perkembangan industri saat ini, dan perkembangan sarana pembangunan, terutama pembangunan gedung sangatlah pesat. Maka tingkat kesulitan untuk mengelola dan menjalankan sebuah proyek gedung semakin tinggi. Semakin tinggi tingkat kesulitannya, berarti semakin semakin panjang durasi waktu yang dibutuhkan untuk menyelesaikan proyek tersebut. Walaupun suatu kegiatan telah direncanakan sebaik mungkin, namun tetap mengandung ketidak pastian bahwa nanti akan berjalan sepenuhnya sesuai rencana. Apabila setelah penambahan waktu pelaksanaan proyek ini juga tidak selesai sesuai kontrak yang sudah disepakati, maka akan diberikan waktu tambahan oleh pihak pemilik (owner) kepada pihak pelaksana untuk menyelesaikan pekerjaan proyek tersebut. Dengan kata lain bahwa adanya waktu tambahan yang diberikan oleh pihak pemilik (owner) kepada pihak pelaksana untuk menyelesaikan pekerjaan proyek, tetapi tidak juga terlaksana, maka kemungkinan akan terjadi pemutusan kontrak kerja.

Dalam pelaksanaan proyek konstruksi tepat waktu, dapat dipastikan menguntungkan kedua belah pihak, oleh sebab itu perusahaan yang baik akan selalu berusaha melaksanakan sesuai waktu yang telah ditetapkan atau berusaha meminimalkan keterlambatan dengan memilih tindakan koreksi yang perlu dilakukan dan mengambil keputusan berdasarkan analisa dari berbagai faktor. Oleh sebab itu diperlukan penelitian untuk mengidentifikasi dan menganalisa faktor-faktor yang mempengaruhi pelaksanaan proyek.

\section{METODOLOGI PENELITIAN Pendahuluan}

Metodologi penelitian merupakan bagian yang memuat tahap-tahap pelasanakaan penelitian mulai dari studi pendahuluan, literatur yang digunakan, metode pemecahan masalah sampai dengan teknik analisis dan kesimpulan. Metodologi juga menjabarkan instrumen yang digunakan dalam penelitian berikut dengan respondennya. Untuk mencapai tujuan suatu penelitian, diperlukan suatu disain/rancangan Penelitian yang didalamnya memuat proses perencanaan dan pelaksanaan penelitian yang sistematis, terorganisasi dan dapat berjalan secara efektif, efisien serta tepat sasaran. Didalam rancangan tersebut dijelaskan mengenai metode penelitian dan analisa yang digunakan sesuai pendekatan yang ditetapkan. Konseptual proses tersebut kemudian dituangkan menjadi suatu metode penelitian lengkap dengan pola analisa observasi serta pengumpulan data yang diperlukan. Dari hasil observasi diperoleh data untuk dilakukan pengolahan menjadi informasi untuk dianalisa dan akhirnya untuk ditarik berbagai kesimpulan yang diperlukan (Singarimbun dan Effendi, 1987).

Adapun kerangka metodologi penelitian dapat dilihat pada Gambar 1.

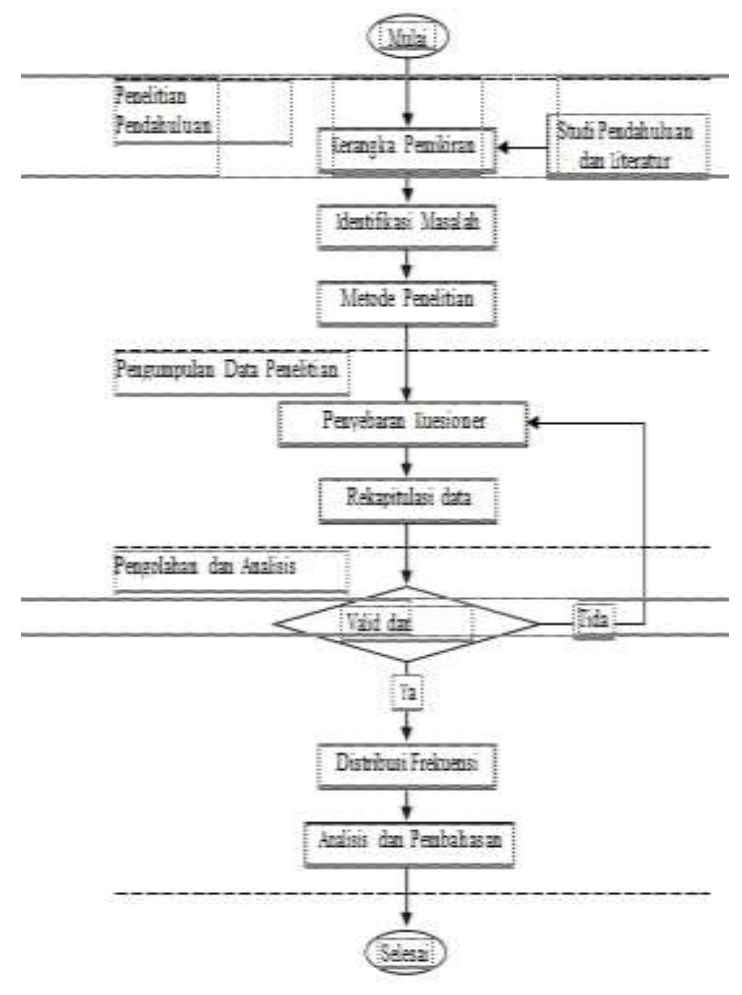


Vol. 2 No.1 Januari 2019

http://jurnal.umsb.ac.id/index.php/RANGTEKNIKJOURNAL

Rang Teknik Journal

Variabel dan Data

Penelitian Variabel adalah objek penelitian, atau apa yang menjadi titik perhatian suatu penelitian. Ada variabel yang mempengaruhi dan variabel akibat. Variabel yang mempengaruhi disebut variabel penyebab atau variabel bebas atau independent variable $(\mathrm{X})$, sedangkan variabel akibat disebut variabel terikat atau tak bebas, atau variabel tergantung atau dependent variable (Y).

Data adalah hasil pencatatan peneliti, baik yang berupa fakta ataupun angka. Berdasarkan pengumpulan data tersebut, diharapkan akan diperoleh data yang akurat mengenai faktor - faktor kritis penentu keterlambatan terhadap pelaksanaan proyek bangunan gedung di Kota Bukittinggi. Teknik analisis data dari hipotesis yaitu faktor - faktor kritis penentu keterlambatan sebagai variabel bebasnya (X), sedangkan proyek bangunan gedung di Kota Bukittinggi sebagai variabel terikatnya (Y).

Sebagai variabel bebas (X) yaitu faktor - faktor kritis penentu keterlambatan terhadap proyek bangunan gedung di Kota Bukittinggi dapat dilihat pada tabel di bawah ini.

Tabel 1. Variabel bebas yang akan dijadikan sebagai bahan kuesioner

Tabel 3.1. Varrabel bebas yang akan dijadikan sebaga bahan kuesioner

\begin{tabular}{|c|c|c|}
\hline Variabel & $\begin{array}{lr}\text { Faktor kritis penentu } \\
\text { keterlambatan } & \text { proyek } \\
\text { bangunan gedung } & \end{array}$ & $\begin{array}{l}\text { Sub. Faktor kritis penentu keterlambatan } \\
\text { proyek bangunan gedung }\end{array}$ \\
\hline $\mathrm{XI}$ & $\begin{array}{l}\text { Faktor lingkup dan kontrak } \\
\text { /dokumen } \\
\text { pekerjann(contract } \\
\text { document) }\end{array}$ & 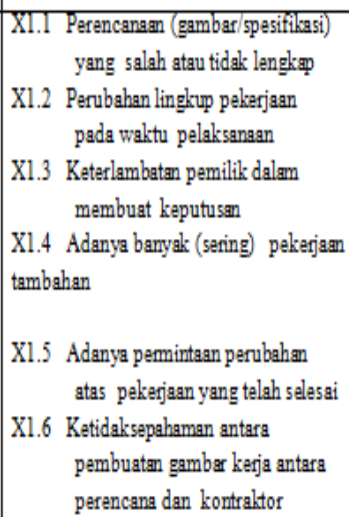 \\
\hline
\end{tabular}

\begin{tabular}{|c|c|c|}
\hline$W$ & 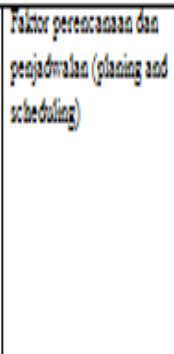 & 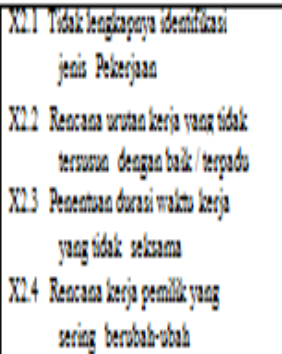 \\
\hline$B$ & $\begin{array}{l}\text { Rimlugand } \\
\text { (magni) }\end{array}$ & 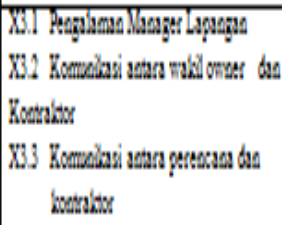 \\
\hline 74 & 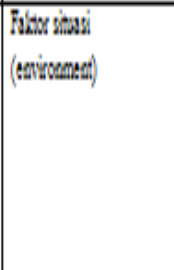 & 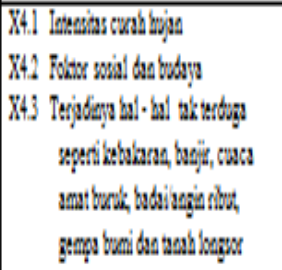 \\
\hline$N$ & his wha (Gagl) & 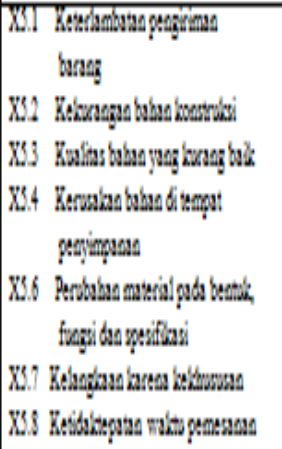 \\
\hline 7 & $\begin{array}{l}\text { himpanding } \\
\text { (wpet) }\end{array}$ & 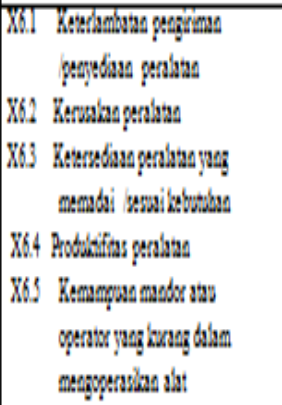 \\
\hline$M$ & $\begin{array}{l}\text { his way hag } \\
\text { (hwm) }\end{array}$ & 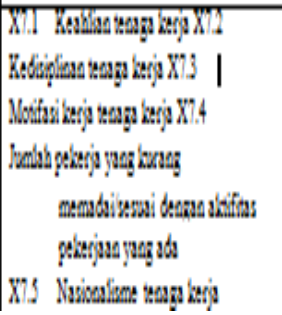 \\
\hline
\end{tabular}




\section{Perancangan Kuesioner Penelitian Penentuan Populasi dan Sampel}

1. Populasi

Populasi adalah wilayah generalisasi yang terdiri dari objek atau subjek yang menjadi kuantitas dan karakteristik tertentu yang ditetapkan oleh peneliti untuk dipelajari dan kemudian ditarik kesimpulannya (Sugiyono, 2011). Jadi populasi merupakan objek atau subjek yang berada pada suatu wilayah dan memenuhi syarat-syarat tertentu yang mempunyai kaitan dengan masalah yang diteliti

Populasi adalah kelompok elemen yang lengkap yang biasanya berupa orang, objek, transaksi, atau kejadian dimana kita tertarik mempelajarinya atau yang menjadi objek penelitian (Arikunto, 2002). Populasi penelitian ini adalah para pelanggan konstruksi yaitu para pengguna jasa kontraktor pada proyek bangunan gedung di kota Bukittinggi.

2. Sampel

Sampel adalah bagian dari jumlah dan karakteristik yang dimiliki oleh populasi (Sugiyono, 2011). Dalam menetapkan ukuran sampel menggunakan metode sensus yaitu jumlah sampel sama dengan jumlah populasi agar peluang kesalahan generalisasi nya kecil, sebagaimana dikemukakan oleh Sugiyono (2011) bahwa makin besar jumlah sampel mendekati populasi, maka peluang kesalahan generalisasi semakin kecil dan sebaliknya makin kecil jumlah sampel menjauhi populasi, maka makin besar kesalahan generalisasi (diberlakukan umum).

Teknik pengambilan sampel pada penelitian ini menggunakan purposive sampling. Purposive sampling adalah teknik penentuan sampel dengan pertimbangan tertentu (Sugiyono, 2011). Pertimbangan yang dilakukan pada penelitian ini adalah orang yang dianggap paling tahu tentang yang diharapkan yaitu direktur perusahaan, site manager, dan Tenaga Ahli terhadap variabel penelitian yaitu faktor Faktor lingkup dan kontrak /dokumen pekerjaan(contract document), Faktor perencanaan dan penjadwalan (planing and scheduling), Faktor Managerial (managerial), 
Faktor situasi (environment), Faktor peralatan (equipment), Faktor tenaga kerja (labors), Faktor keuangan (financing), Faktor perubahan (change), Faktor karakteristik tempat (site characteristic), Faktor sistem inspeksi, kontrol dan evaluasi pekerjaan Sampel/ Responden dari stakeholder yang dimaskud dalam penelitian ini adalah para pemilik proyek (owner) yang dapat diwakilkan oleh manajemen konstruksi/ konsultan pengawas/tim teknis ataupun perwakilan pemilik proyek yang lain yang yang lain setingkat manajerial dan teknis yang berkompeten, yang pernah menggunakan jasa kontraktor untuk proyek bangunan gedung di kota Bukittinggi

\section{Pengumpulan data penelitian}

Menurut Gulo (2002), pengumpulan data dilakukan untuk memperoleh informasi yang dibutuhkan dalam rangka mencapai tujuan penelitian, dimana tujuan yang diungkapkan merupakan asumsi sementara terhadap pertanyaan penelitian, sehingga jawabannya masih perlu diuji secara empiris, dan untuk maksud inilah dibutuhkan pengumpulan data. Data yang akan diteliti dan dianalisis dalam penelitian ini terdiri dari 2 (dua) data, yaitu data primer dan data sekunder.

\section{Data Primer}

Data primer didapat dengan melakukan studi lapangan. Studi lapangan merupakan cara pengumpulan data dengan melakukan survey kepada perusahaan-perusahaan kontraktor, pihak owner serta pihak pihak yang berkaitan dan berkompeten terhadap permasalahan yang diteliti. Pendekatan untuk pengumpulan data primer dilakukan dengan cara survey. Survey merupakan suatu metode yang sistematis untuk mengumpulkan data berdasarkan suatu sampel agar mendapatkan informasi dari populasi yang serupa (Tan 1995). Selain itu tujuan utama dari survey bukan untuk menentukan suatu kasus yang spesifik, namun untuk mendapatkan karakteristik utama dari populasi yang dituju pada suatu waktu yang telah ditentukan (Naoum 1999). Sebagai landasan teori dalam pengumpulan data primer, dilakukan studi literatur melalui buku-buku, jurnal, majalah dan artikel.

Dalam penelitian ini teknik atau metode pengumpulan data yang akan dilakukan adalah dengan cara menyiapkan kuesioner. Kuesioner dibuat untuk memperoleh data primer yang disusun berdasarkan parameterparameter analisis yang dibutuhkan. Hal ini juga harus relevan sesuai dengan maksud dan tujuan penelitian.

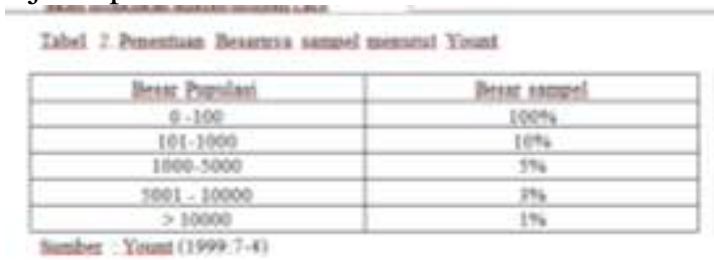

\section{HASIL DAN PEMBAHASAN}

Berisikan hasil analisis penelitian dan pembahasan tentang Faktor Penyebab Keterlambatan Proyek Bangunan Gedung Pemerintah di Kota Bukittinggi. Adapun teknik analisis statistik yang digunakan adalah uji validitas menggunakan pearson correlation dan uji reliabilitas menggunakan Cronbach's alpha.

Talts S Penyubaras Kaesiones

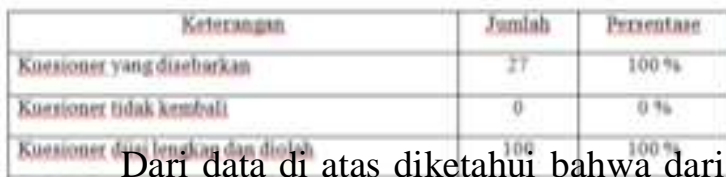
27 eksemplar kuesioner yang dikembalikan oleh responden. Seluruh kuesioner yang kembali tersebut diisi lengkap oleh responden sehingga dapat diolah sebagai data penelitian.

\section{Profil Responden}

Jumlah responden yang dituju dalam pelaksanaan survei ini adalah sebanyak 27 orang yang mewakili jasa pengguna kontraktor (Direktur, Site manajer, Tenaga Ahli Perusahaan), PPTK dan Pejabat Penerima Barang yang terlibat didalam rangkaian pekerjaan proyek Konstruksi Gedung di Kota Bukittinggi. Kuesioner yang dikembalikan layak untuk diolah. Dari hasil analisis statistik deskriptif diperoleh responden dengan jabatan dapat dilihat seperti dalam tabel 4 berikut. 


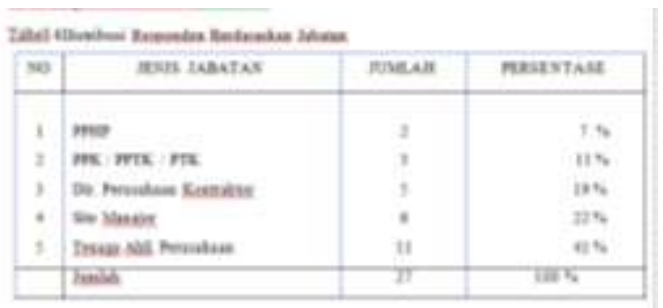

\section{Uji Validitas dan Reliabilitas}

Sebelum dilakukan analisis terhadap data hasil penelitian maka terlebih dahulu dilakukan pengujian instrumen untuk mendapatkan instrumen yang sahih (valid) dan handal (reliabel) secara empiris agar hasil interpretasi tidak bias. Pengujian instrumen pada penelitian ini dilakukan setelah penelitian, selanjutnya butir pertanyaan yang tidak valid akan dibuang dan tidak dimasukkan ke dalam analisis berikutnya.

\section{Uji Validitas}

Uji validitas bertujuan untuk mengetahui sejauh mana validitas yang didapat dari penyebaran kuesioner yang diukur benar-benar menyatu satu sama lainnya. Validitas didefenisikan sebagai ukuran seberapa cermat suatu tes melakukan fungsi ukurannya. Suatu alat ukur yang valid tidak sekedar mengungkapkan data dengan tetap, akan tetapi juga harus memberikan gambaran mengenai data tersebut. Suatu tes atau instrumen pengukur dikatakan mempunyai validitas yang tinggi apabila alat ukur tersebut menjalankan fungsi atau memberikan hasil ukurannya yang sesuai dengan maksud dilakukannya pengukuran. Adapun hasil uji validitas dari variabel-variabel penelitian dapat dilihat pada bagian dibawah berikut ini :

Tabel 5 Rekapitulasi Hasil Uji Validitas Faktor

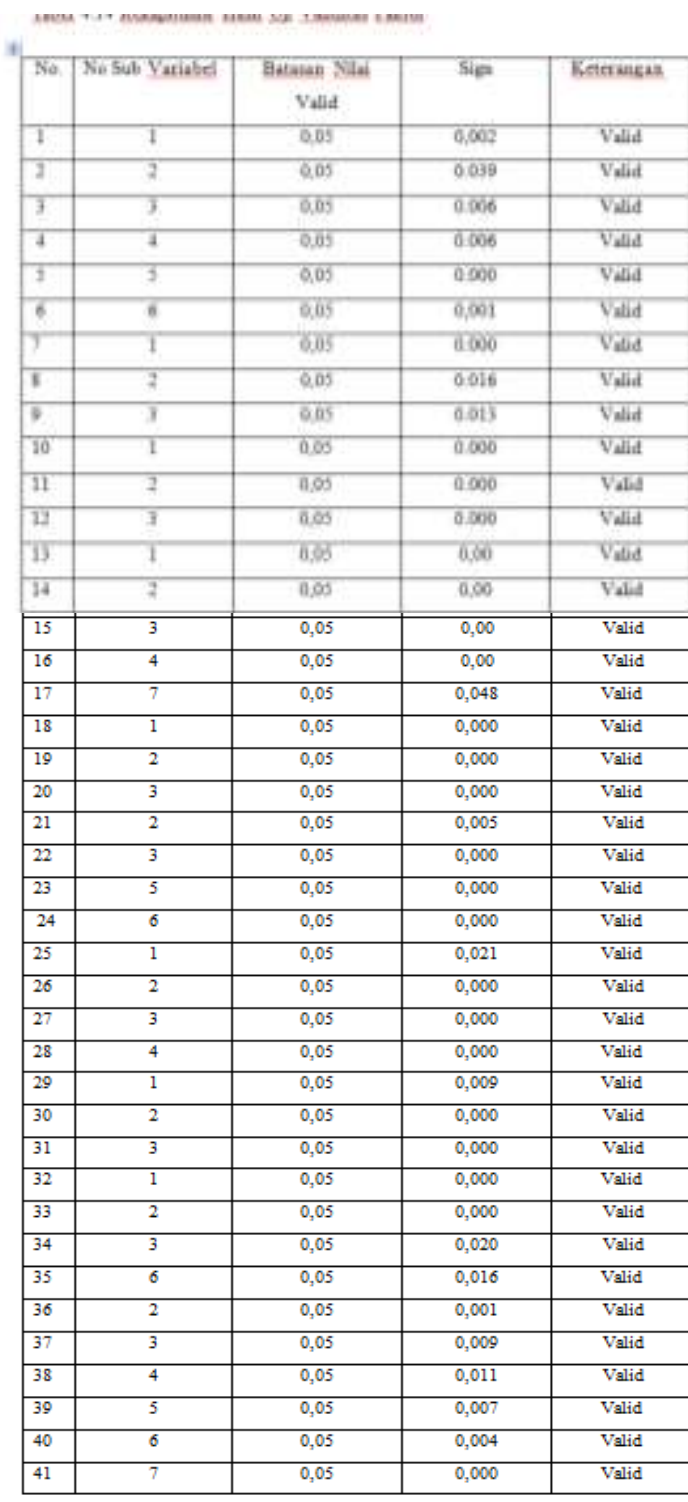

Sumber hasil pengolahan SPSS.16

\section{Uji Reliabilitas}

Uji reliabilitas adalah suatu uji yang menunjukan sejauh mana pengukuran itu dapat memberikan hasil yang relatif tidak beda, jika dilakukan pengulangan pengukuran terhadap subjek yang sama. Uji ini hanya dapat dilakukan pada pertanyaan-pertanyaan yang valid saja.Uji Reliabilitas menggunakan batasan nilai Cronbach's Alpa 0,6, jika nilai Cronbach's Alpha < 0,6 adalah kurang baik, nilai 0,7 dapat diterima dan diatas 0,8 adalah baik (Sakaran1992.5) maka item-item pertanyaan yang valid tersebut dinyatakan reliabel dan variabelnya layak untuk diproses dalam pengujian hipotesis. 
Tabel 6 Hasil Uji Reliabilitas

\begin{tabular}{|c|c|c|}
\hline Tar Eatinut & 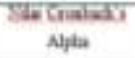 & zeden an \\
\hline 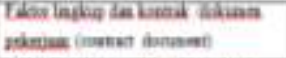 & $3 e^{2}$ & 8 \\
\hline 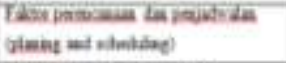 & 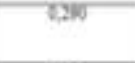 & $\mathrm{J}$ \\
\hline 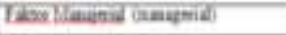 & 2354 & 3 \\
\hline 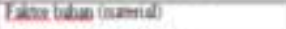 & D,, 81 & 3 \\
\hline 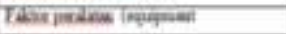 & ग01 & $\mathrm{T}$ \\
\hline 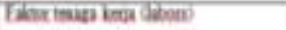 & Dका & $\bar{T}$ \\
\hline 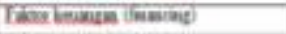 & 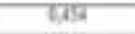 & $i$ \\
\hline 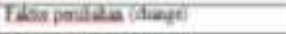 & EहT & 3 \\
\hline 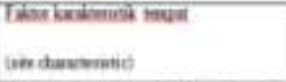 & पका & $T$ \\
\hline 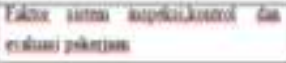 & एक & 8 \\
\hline
\end{tabular}

Imin lad gaulea sps.it

Hasil uji reliabilitas pada Tabel 6 terlihat bahwa Faktor Bahan (material), Faktor Faktor peralatan (equipment), Faktor tenaga kerja (labors) dan Faktor karakteristik tempat nilai Cronbach Alpha antara 0,611-0,767 > 0,60 . Hal ini menandakan bahwa keseluruhan faktor di dalam penelitian ini merupakan faktor yang reliabel dan layak untuk diuji dan dianalisa korelasinya dalam penelitian ini. Dari hasil Reliabilitas yang telah dilaksanakan, maka diperoleh bahwa Faktor Penyebab Keterlambatan Proyek Bangunan Gedung di Kota Bukittinggi. adalah sebagai berikut :

1. Faktor bahan (material) yang mempunyai 7 Sub Variabel dinyatakan 5 Sub Variabel adalah valid yang artinya bahwa Faktor bahan (material) merupakan Faktor Penyebab Keterlambatan Proyek Bangunan Gedung di Kota Bukittinggi

2. Faktor peralatan (equipment)yang mempunyai 5 Sub Variabel, dinyatakan 3 Sub Variabel yang dinyatakan valid yang artinya Faktor peralatan (equipment) merupakan Faktor Penyebab Keterlambatan Proyek Bangunan Gedung di Kota Bukittinggi.

3. Faktor tenaga kerja labors) yang mempunyai 6 Sub Variabel dinyatakan 4 Sub Variabel yang dinyatakan valid yang artinya Faktor tenaga kerja (labors) merupakan Faktor Penyebab Keterlambatan Proyek Bangunan Gedung di Kota Bukittinggi.
4. Faktor Karakteristik Tempat (Site characteristic) yang mempunyai 7 Sub Variabel dinyatakan 4 Sub Variabel yang dinyatakan valid yang artinya Faktor karakteristik tempat (site characteristic) merupakan Faktor Penyebab Keterlambatan Proyek Bangunan Gedung di Kota Bukittinggi.

Dengan demikian dari 10 faktor yang diteliti, terdapat 6 faktor yang tereliminasi dari instrument penelitian. Oleh karenanya terdapat 4 faktor yang Relialibilitas dengan 16 variabel yang valid.

\section{Analisis Faktor}

Untuk menyederhanakan jumlah faktor - faktor Penyebab Keterlambatan Proyek Bangunan Gedung di Kota Bukittinggi, penyederhanaan dilakukan terhadap 16 butir pertanyaan yang diperoleh dari hasil uji validitas dan uji reliabilitas. Tujuan dari penyederhanaan faktor penting ini adalah untuk mempermudah dalam mendapatkan variabel dominan dengan interkorelasi antar variabel sekecil mungkin.

Hasil analisis dari 16 butir pertanyaan yang dianalisis dapat dilihat pada Total Variance Explained dan Rotated Component Matrix yang menjadikan 6 faktor seperti disajikan pada Tabel 7:

Tabel 7 Hasil Uji Analisa Faktor (Total Variance Explained)

\begin{tabular}{|c|c|c|c|c|c|c|}
\hline \multirow[b]{2}{*}{ gont } & \multicolumn{3}{|c|}{ 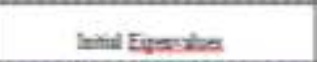 } & \multicolumn{3}{|c|}{$\begin{array}{c}\text { Exase San of } 5 \text { pas } \\
\text { Leatup }\end{array}$} \\
\hline & Toul & $\begin{array}{l}\text { Sof } \\
\text { virimen }\end{array}$ & Caler & Toul & $\begin{array}{l}\text { Sef } \\
\text { Varias? }\end{array}$ & Cantert \\
\hline I & 428 & 21289 & 21.36 & 453 & 23159 & 2826 \\
\hline 2 & 2607 & $16 \mathrm{x} 4$ & L4se3 & 2.501 & 16.99 & 44567 \\
\hline 3 & 2159 & Eas & seoss & 218 & II 25 & savs \\
\hline 4 & 1307 & 2796 & 65351 & $12 x$ & 7.396 & 65151 \\
\hline 5 & 1054 & fised & rases & 1004 & 6.54 & 72494 \\
\hline 6 & 1095 & 6.4se & 78964 & 1035 & 6.456 & 78964 \\
\hline 7 & s:6 & 504 & sucse & & & \\
\hline 8 & 34] & 3 act & 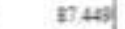 & & & \\
\hline \$ & sos & 3.158 & $90 \mathrm{sec}$ & & & \\
\hline 10 & 48 & $2 * 0$ & $5 \% 39$ & & & \\
\hline It & 345 & 2150 & $\$ 5755$ & & & \\
\hline 12 & 280 & $1 \mathrm{ses}$ & 97343 & & & \\
\hline 13 & 159 & $\sec$ & 94374 & & & \\
\hline 14 & 14: & s2: & 95.363 & & & \\
\hline 15 & set & ses: & sasced & & & \\
\hline is & 091 & 234 & 200000 & & & \\
\hline
\end{tabular}

Extraction Method: Principal Component analysis.

Berdasarkan Tabel 4.16 diketahui bahwa dari 16 butir pertanyaan yang dianalisis 
faktor, diperoleh menjadi 6 ( enam ) faktor (nilai eigen value $>1$ ). Faktor $1 \mathrm{mampu}$ menjelaskan $28.269 \%$ variasi, faktor 2 mampu menjelaskan $16.294 \%$ variasi, faktor 3 mampum enjelaskan $13.492 \%$ variasi. Factor 4 mampu menjelaskan $7.796 \%$ variasi, factor 5 mampu menjelaskan $6.648 \%$ variasi, factor 6 mampu menjelaskan $6.466 \%$ variasi. Secara keseluruhan, keenam faktor tersebut mampu menjelaskan $78.964 \%$ variasi

\section{SIMPULAN}

Berdasarkan hasil dari analisis dan pembahasan dapat diambil kesimpulan. Hasil analisa data menunjukan ada enam sub faktor utama yang sangat berpengaruh terhadap kinerja waktu pelaksanaan proyek konstruksi gedung di kota Bukittinggi, sub faktor tersebut adalah:

1. Keterlambatan pengiriman Barang dengan nilai Eigen Value sebesar $28,269 \%$

2. Kekurangan Bahan Konstruksi dengan nilai Eigen Value sebesar 16,294 \%

3. Kualitas Bahan yang kurang baik dengan nilai Eigen Value sebesar $13,492 \%$

4. Kerusakan bahan ditempat penyimpanan dengan nilai Eigen Value sebesar 7,796\%

5. Ketidak tepatan waktu pemesanan dengan nilai Egien Valua sebesar $6,648 \%$

6. Keterlambatan pengiriman/penyediaan peralatan dengan nilai Eigen Value sebesar $6,466 \%$

\section{SARAN}

Untuk mengatasi keterlambatan ini, pihak-pihak yang terlibat dalam pembangunan proyek konstruksi gedung harus melakukan beberapa cara atau strategi diantaranya: Penjadwalan pengiriman material yang harus benar benar tersusun dengan teratur dan efektif, mengantisipasi dengan cepat terhadap kekurangan maerial dilapangan, menjaga kualitas barang yang dikirim ke proyek agar mengikuti spesifikasi yang ada, menyediakan tempat penyimpanan material yang layak dan memadai, menyusun jadwal permintaan material dari lapangan yang tepat, menyediakan peralatan utama yang dibutuhkan sesuai dengan waktu pelaksanaan pekerjaan. Dalam pembangunan suatu proyek konstruksi, sebaiknya metode pelaksanaan dan manajemen pelaksanaan proyek dapat diperhatikan yang lebih karena peranan metode pelaksanaan dan manajemen pelaksanaan sangat penting mulai dari awal sampai akhir pelaksanaan proyek gedung.

\section{DAFTAR PUSTAKA}

Abrar, Husein. 2008. Manajemen Proyek, perencanaan, penjadwalan \& pengendalian proyek. Yogyakarta : Andi.

Bramantyo Djohanputro, (2008), Manajemen Resiko Korporat, (Jakarta : Penerbit PPM

Darmawi, Herman. 2005. Manajemen Resiko. Bumi Aksara, Jakarta.

Effendi Sofian. 1987.Metode Penelitian Survai. Kota : PT. Pustaka LP3ES Indonesia.

Ervianto, Wulfram I. 2004. Teori- Aplikasi Manajemen Proyek Konstruksi. Yogyakarta : Andi.

I Gede Putu joni. 2012. Resiko Manajemen Proyek. Jurnal Teknik Sipil. 16:48-55.

Santosa, Budi. 2009. Manajemen Proyek: Konsep \& Implementasi. Yogyakarta: Graha Ilmu

Soeharto, Iman. 1998. Manajemen Proyek dari Konseptual sampai Operasional Jilid II. Jakarta : PT. Gelora

Aksara Pratama. Duwi Priyatno, 2012.Belajar cepat Olah Data Statistik dengan SPSS: Andi, Jogjakarta 